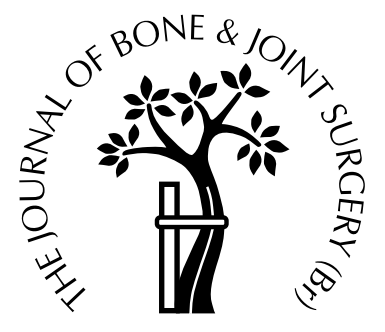

\title{
Congenital insensitivity to pain
}

\author{
ORTHOPAEDIC MANIFESTATIONS
}

\author{
E. Bar-On, D. Weigl, R. Parvari, K. Katz, R. Weitz, T. Steinberg \\ From the Schneider Children's and Rabin Medical Centres, Petah Tikva and Ben \\ Gurion University, Beer-Shiva, Israel
}

$\mathbf{W}$ e reviewed 13 patients with congenital insensitivity to pain. A quantitative sweat test was carried out in five and an intradermal histamine test in ten. DNA examination showed specific mutations in four patients. There were three clinical presentations: type $A$, in which multiple infections occurred (five patients); type B, with fractures, growth disturbances and avascular necrosis (three patients); and type $C$, with Charcot arthropathies and joint dislocations, as well as fractures and infections (five patients, four with mental retardation).

Patient education, shoeware and periods of non-weight-bearing are important in the prevention and early treatment of decubitus ulcers. The differentiation between fractures and infections should be based on aspiration and cultures to prevent unnecessary surgery. Established infections should be treated by wide surgical debridement. Deformities can be managed by corrective osteotomies, and shortening by shoe raises or epiphysiodesis. Joint dislocations are best treated conservatively.

J Bone Joint Surg [Br] 2002;84-B:252-7.

Received 28 November 2000; Accepted 11 January 2001

Congenital insensitivity to pain is a rare condition which may affect various tracts in the peripheral nervous system. There is an indifference to painful stimuli, and in most patients the autonomic nervous system is affected. The condition has therefore been described as hereditary senso-

E. Bar-On, MD, Director

D. Weigl, MD, Senior Surgeon

K. Katz, MD, Senior Surgeon

Paediatric Orthopaedic Unit

R. Weitz, MD, Director

T. Steinberg, MD, Attending Physician

Child Neurology Unit

Schneider Children's Medical Centre, 14 Kaplan Street, Peteh Tikva 49202, Israel.

R. Parvari, $\mathrm{PhD}$

Department of Microbiology and Immunology, Faculty of Health Sciences, Ben Gurion University, Beer Sheva, Israel.

Correspondence should be sent to Dr E. Bar-On.

(C)2002 British Editorial Society of Bone and Joint Surgery 0301-620X/02/211939\$2.00 ry and autonomic neuropathy (HSAN) with various subtypes being described. ${ }^{1}$ Musculoskeletal manifestations are very common although the pathology, inheritance, and pathophysiology of these, as well as their relationship to the different subtypes, have only been partially clarified, mainly in case reports. ${ }^{2-17}$

We describe our experience of 13 patients with congenital insensitivity to pain. They had multiple musculoskeletal problems which included infections, fractures, growth disturbances, avascular necrosis (AVN), Charcot arthropathy, joint dislocations and heterotopic ossification. The multitude and severity of these problems, as well as the additional non-orthopaedic manifestations, presented complex diagnostic and therapeutic dilemmas.

\section{Patients and Methods}

There were 13 patients (five boys and eight girls) with a mean age at presentation of 13 years ( 5 to 25). All affected siblings had been located and included in the study. All had a thorough orthopaedic and neurological examination and the available records and radiographs were studied. Ten underwent a histamine test by the intradermal injection of $0.05 \mathrm{ml}$ of a $1 / 10000$ solution of histamine phosphate. A normal response consists of a local weal surrounded by a painful erythematous flare extending for 1 to $3 \mathrm{~cm}$. In a pathological response the flare is absent and the pain minimal.

A quantitative sweat test was undertaken in five patients by the application to the forearm of a gauze pad saturated with $0.4 \%$ pilocarpine. A low voltage $(5 \mathrm{~mA})$ electric current was then passed between two points $3 \mathrm{~cm}$ apart for five minutes. Sweat was collected on blotting paper applied to the area and sealed with polyethylene for 30 minutes. A normal response is the production of over $80 \mathrm{mg}$ of sweat.

DNA was prepared and tested for mutations in exons 15 and 16 of the TrkA gene as described by Shatzky et al. ${ }^{18}$

\section{Results}

Table I gives the clinical details and systemic findings in the patients. There were three pairs of siblings, one group of three siblings and four unrelated patients. All had addi- 
Table I. Details of the 13 patients with congenital insensitivity to pain

\begin{tabular}{|c|c|c|c|c|c|c|c|c|c|c|c|c|c|c|}
\hline Case & $\begin{array}{l}\text { Age } \\
\text { (yrs) }\end{array}$ & Gender & Descent* & $\begin{array}{l}\text { Consangineous } \\
\text { parents }\end{array}$ & $\begin{array}{l}\text { Affected } \\
\text { siblings }\end{array}$ & $\begin{array}{l}\text { Healthy } \\
\text { siblings }\end{array}$ & $\begin{array}{l}\text { Age at } \\
\text { diagnosis } \\
\text { (yrs) }\end{array}$ & Retardation & Mutation & Fractures & $\begin{array}{l}\text { Amputated } \\
\text { fingers }\end{array}$ & $\begin{array}{l}\text { Amputated } \\
\text { toes }\end{array}$ & $\begin{array}{l}\text { Type } \\
\text { (Dyck) }\end{array}$ & $\begin{array}{l}\text { Type } \\
\text { (present } \\
\text { study) }\end{array}$ \\
\hline 1 & 12 & $\mathrm{~F}$ & ABS & + & 1 & 7 & 5 & Normal & - & 6 & 1 & 6 & VI & B \\
\hline 2 & 11 & $\mathrm{~F}$ & ABS & + & 1 & 7 & 6 & Normal & - & 1 & & & VI & $\mathrm{B}$ \\
\hline 3 & 10 & $\mathrm{~F}$ & ABS & - & 0 & 3 & 3.5 & Moderate & 1926-Ins-T & 4 & 1 & 1 & IV & $\mathrm{C}$ \\
\hline 4 & 6 & M & JM & - & 1 & 1 & 0 & Severe & - & 2 & 1 & & IV & $\mathrm{C}$ \\
\hline 5 & 13 & $\mathrm{~F}$ & $\mathrm{JM}$ & - & 1 & 1 & 1 & Severe & - & 1 & 4 & & IV & $\mathrm{C}$ \\
\hline 6 & 5 & $\mathrm{~F}$ & $\mathrm{ABN}$ & + & 2 & 6 & 0 & Moderate & Pro-689-Leu & 0 & 4 & & IV & A \\
\hline 7 & 10 & $\mathrm{~F}$ & $\mathrm{ABN}$ & + & 2 & 6 & 0 & Moderate & Pro-689-Leu & 0 & 9 & 2 & IV & A \\
\hline 8 & 14 & M & $\mathrm{ABN}$ & + & 2 & 6 & 0.33 & Moderate & Pro-689-Leu & 4 & & & IV & $\mathrm{C}$ \\
\hline 9 & 24 & M & AP & + & 0 & 7 & 11 & Normal & - & 1 & & 1 & I & A \\
\hline 10 & 9 & $\mathrm{~F}$ & AP & + & 0 & 2 & 1.5 & Normal & - & 7 & & & VI & B \\
\hline 11 & 12 & $\mathrm{~F}$ & $\mathrm{AP}$ & + & 1 & 3 & 2 & Normal & - & 0 & 3 & 5 & II & A \\
\hline 12 & 25 & M & $\mathrm{AP}$ & + & 1 & 3 & 11 & Normal & - & 0 & 10 & $\begin{array}{l}2 \\
\text { (below knee) }\end{array}$ & II & A \\
\hline 13 & 19 & M & $\mathrm{JM}$ & - & 0 & 3 & 0.58 & Normal & - & 5 & 2 & & IV & $\mathrm{C}$ \\
\hline
\end{tabular}

* ABS, Bedouins from the South; ABN, Bedouins from the North; JM, Moroccan Jews; AP, non-Bedouin Palestinians

tional healthy siblings, none had other known affected relatives in previous generations and none had borne offspring. The parents of nine of the patients were either first or second cousins and none of the families was known to be related to each other. Ten patients were of Arab origin; three Bedouin siblings from northern Israel, three Bedouins from southern Israel and four non-Bedouin Palestinians. Three patients in two families were of Moroccan-Jewish descent.

The age at diagnosis ranged from the neonatal period to 11 years. The presenting symptoms varied and included unexplained fevers, tongue-biting, multiple skin wounds, fractures (some presenting late as painless swelling), and sepsis as a result of osteomyelitis. Self-mutilation of the tongue or fingers was found in 11 patients. Six suffered from mental retardation and behavioural disturbances, although the degree of this was very variable.

The control of body temperature was abnormal in 11, and clinical anhidrosis was present in 12 . Four (cases 6,8 , 9 and 13) underwent a quantitative sweat test which gave a result of 4.0 to $13.0 \mathrm{mg} /$ hour, considerably below normal values. The only patient without clinical anhidrosis (case 10) produced $130 \mathrm{mg} /$ hour which was within normal limits. Postural hypotension was found in one patient.

Although a decreased sensitivity to pain was present in all patients, the degree of this deficit was very variable both between different patients as well as in locations in the same patient, with distal areas being more severely affected. While the various sensory tracts were examined clinically in all patients, the responses were considered to be unreliable in five because of their mental retardation. Surface pinpricking produced apprehension in all patients. A decrease or absence of sensation to touch was found in three of eight patients, impaired temperature discrimination in four of eight and decreased vibration sense in three of eight. Proprioception was absent in four of eight. The axon reflex response to an intradermal histamine injection was absent in eight of ten patients (cases 1,2, 5 to 8, 12 and 13) and normal in two (cases 3 and 10).

Musculoskeletal problems. We found a wide range of musculoskeletal disorders affecting both upper and lower limbs (Table I). No spinal problems or motor deficit were found in any patient. Gait was impaired only by structural deformities or infection of the lower limb. Our patients presented with one of the following three distinct patterns of musculoskeletal involvement.

Type A. Five of our patients were of this type (cases 6, 7, 9, 11 and 12). The hallmark was multiple infections which usually started as infected decubitus ulcers either on weight-bearing areas in the feet (Fig. 1) or as infected bursitis around the knees or elbows, progressing to chronic osteomyelitis or septic arthritis. The diagnosis was complicated by concomitant infections at multiple sites as well as defective temperature control masking systemic manifestations.

Treatment consisted of a combination of antibiotics and relief of pressure from weight-bearing areas, either by custom-made shoeware, weight-relieving casts, or periods of non-weight-bearing. All patients eventually required surgical treatment, which included drainage, wide debridement, amputation of toes in one, excision of the fifth ray in one, and a below-knee amputation in another. There was only one fracture in this group. Two of the patients were moderately retarded.

Type $B$. The three patients with this type (cases 1, 2 and 10) had fractures, avascular necrosis and disturbances of growth. The number of known fractures are shown in Table I. They were predominantly in the lower limbs. The distribution of fractures in the whole group is summarised in Table II. The diagnosis of these fractures was often delayed. All but one fracture was treated non-operatively and united with profuse callus. A fracture of the femoral 


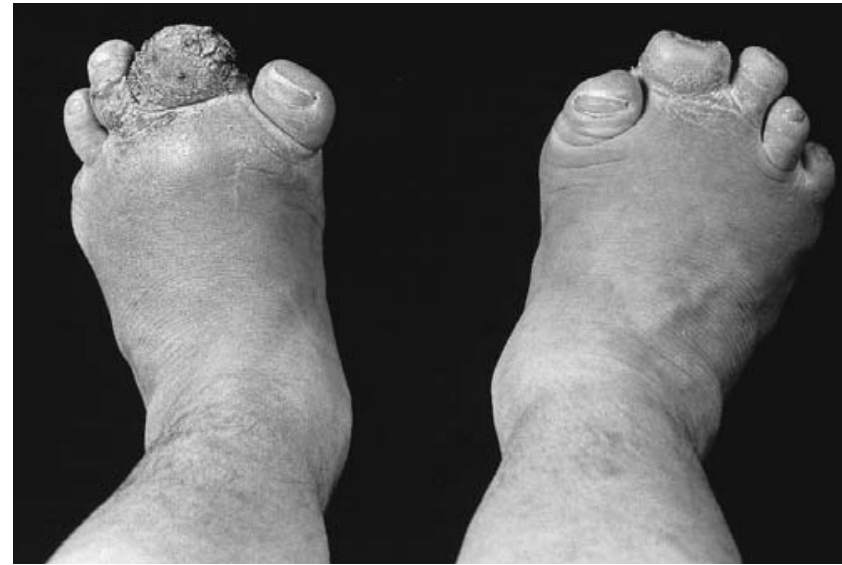

Fig. 1a

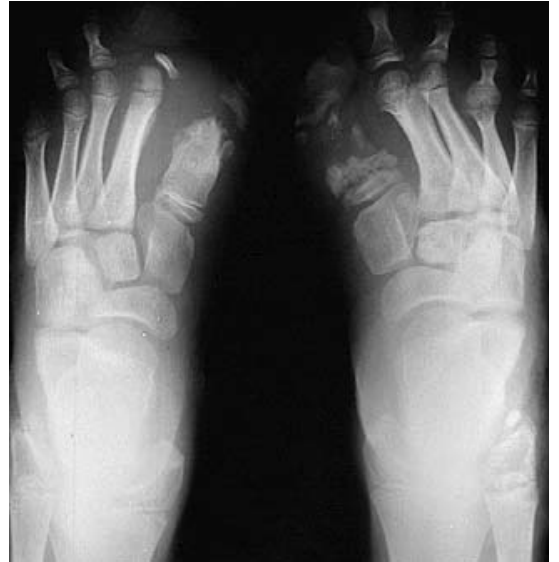

Fig. 1b

Case 11. Photograph (a) and radiograph (b) of the feet of a type-A patient showing severe infection of the toes progressing to chronic osteomyelitis.

Table II. Sites of fractures for the 13 patients with congenital insensitivity to pain

\begin{tabular}{lc}
\hline Site & $\begin{array}{c}\text { Number of } \\
\text { fractures }\end{array}$ \\
\hline Humerus & 1 \\
Forearm & 2 \\
Femoral neck & 2 \\
Femoral shaft & 5 \\
Distal femoral epiphysis & 2 \\
Tibia & 12 \\
Os calcis & 4 \\
Metatarsals & 3 \\
Total & 31 \\
\hline
\end{tabular}

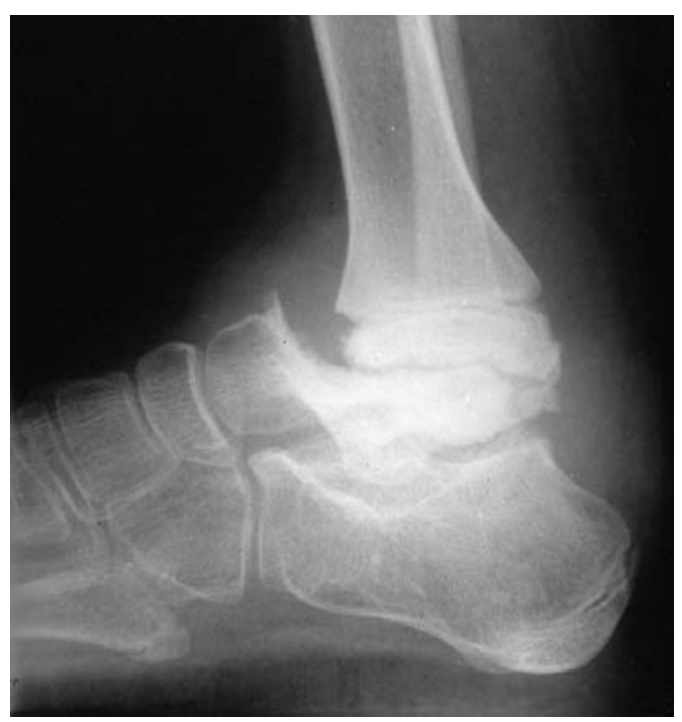

Fig. 2

Case 2. Radiograph showing AVN of the talus in a type-B patient. neck was treated by percutaneous screw fixation which failed. It developed into pseudarthrosis but the patient remains mobile. All three patients had AVN of one talus (Fig. 2) and one had AVN of the medial femoral condyle with a varus deformity of the knee (see Fig. 4a). All had growth disturbances around the knees resulting in unilateral genu varum in one, unilateral genu valgum in another, and a severe windswept deformity in the third. Some of the growth disturbances were attributable to fractures of the growth plate, but in others there was no known preceding injury. Two were treated surgically. One (case 1) underwent a corrective osteotomy of the distal femur. The deformity recurred and she underwent a further osteotomy and hemiepiphysiodesis with a corrective osteotomy of the contralateral proximal tibia, because of a severe windswept deformity (Fig. 3). Another (case 10) underwent a corrective osteotomy of the right proximal tibia and an epiphysiodesis of the proximal fibula (Fig. 4). All osteotomies united uneventfully and there were no problems with wound healing. At follow-up at three and two years respectively, there was no sign of recurrent deformity.

Although in one of these patients aged five years the presenting symptom was septic shock secondary to osteomyelitis of the humerus, in general, infections were uncommon in this group. Intelligence was normal and their minor behavioural problems were attributable to the fact that they spent much of their lives in hospital, as well as to the stigma which they carry in their environment; one is labelled as the village witch.

Type $C$. Five patients (cases 3 to 5, 8 and 13) presented with Charcot arthropathies, joint dislocations, infections and fractures. One was of normal intelligence, but the other four showed mental retardation and behavioural disturbances of varying severity. The joint manifestations were the hallmark of this group, but they also suffered multiple bone and joint infections requiring many surgical procedures. 
Attempts at surgical stabilisation of the joints were mainly unsuccessful. A talectomy and an attempted tibiocalcaneal fusion in one patient resulted in a severely infected pseudarthrosis which resolved after multiple surgical debridements and prolonged treatment with antibiotics. Two patients had operations on Charcot-type knees. Stability was not improved by surgery and these patients are managed by braces which often have to be modified because of pressure ulceration. Dislocation of the hip was found in three patients, with one (case 13) having recurrent dislocations of the left side. He was treated by a hip spica but sustained a distal femoral fracture after it had been removed, and further immobilisation in a cast was required. The hip stabilised and the patient regained the ability to walk. The girl (case 5) with a long-established dislocation of the hip at presentation was a non-walker because of other severe deformities of the limbs and infections; this dislocation therefore was no disability to her. Her younger brother, who was an active walker, had a unilateral dislocation with gross asymmetry. He underwent an open reduction combined with varus derotation osteotomy of the femur and a Salter pelvic osteotomy. The hip subsequently redislocated with the additional complications of heterotopic ossification and a fracture distal to the femoral plate. Eventually, the contralateral hip dislocated and the child has a symmetrical, if somewhat waddling, gait (Fig. 5).

Genetic studies. All patients were tested for the two mutations found in the Arab Bedouin Israeli population by Shatzky et al. ${ }^{18}$ Mutations were found in four patients. One (case 3) was found to have mutation 1926-1ns-T. This patient was a Bedouin Arab from southern Israel. The mutation was not found in two patients (cases 1 and 2) who

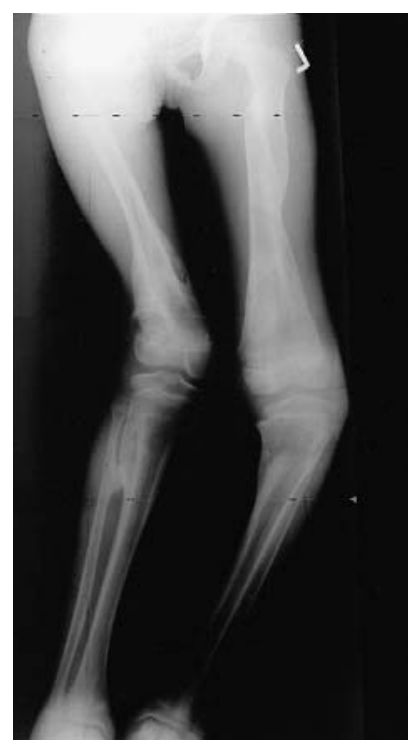

Fig. 3a

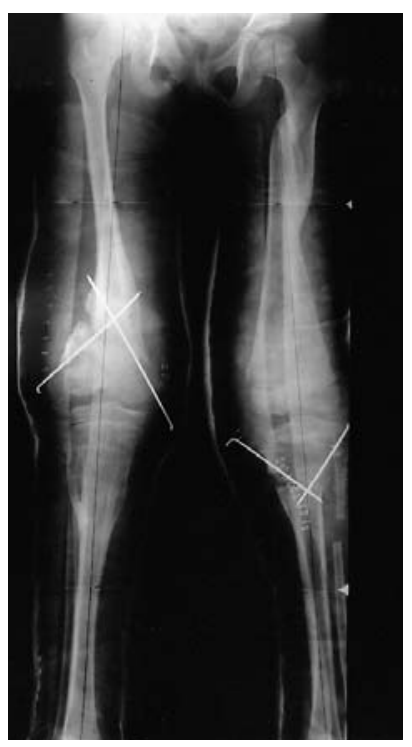

Fig. 3b
Case 1. Radiographs showing a) a windswept deformity in a type-B patient with previous fractures of both femora and tibiae around the knees and a fracture of the left femoral shaft, and b) after corrective osteotomies of the right distal femur and left proximal tibia. were of similar origin. Three patients (cases 6 to 8) who were siblings of Bedouin Arab descent from the northern part of Israel showed a Pro-689-Leu mutation on the TrkA gene. There were no additional patients of similar descent.

\section{Discussion}

'Painless whitlows', 'mal perforant du pied' and 'Morvan syndrome' are some of the many names used to describe a wide range of conditions which we group under HSAN. Common to all these conditions is an insensitivity to pain, but in addition to their analgesia, proprioception, temperature sensitivity and vibratory sensation may also be affected and some have wider systemic problems. Since the first description by Leplat in 1846, numerous reports of patients with variants of the condition have appeared. Various investigators have studied the systemic and genetic aspects of the condition. A review of the orthopaedic literature shows that 24 cases $^{2-13,15,16}$ have been described.

Various classification systems have been proposed based on the mode of inheritance, natural history, pathological alterations, neurophysiological characteristics and biochemical disorders. Those more widely accepted were proposed by Pinsky and DiGeorge ${ }^{14}$ in 1966 and more recently by Dyck ${ }^{1}$ in 1984 who divided these neuropathies into five types. Type I is a relatively mild condition, manifesting in the second to fourth decade and mainly affecting the lower limbs. Type II is a more severe form presenting in infancy or early childhood. All four limbs and possibly the trunk are involved. Sweating is absent, but temperature and

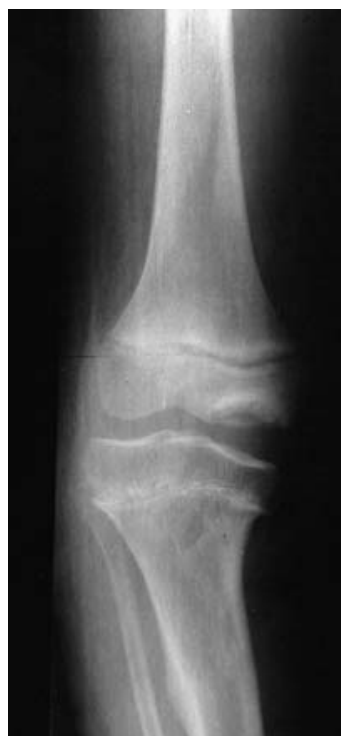

Fig. $4 \mathrm{a}$

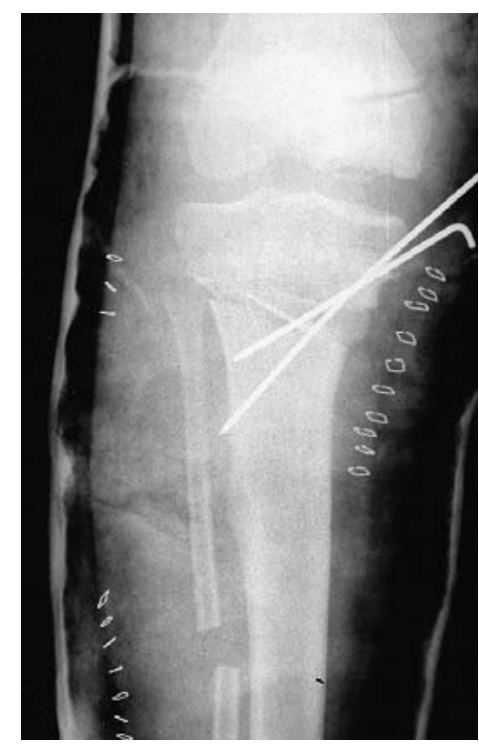

Fig. $4 \mathrm{~b}$
Case 10. Radiographs of a fracture of the tibial shaft in a type-B patient showing a) persistent deformity with AVN of the medial femoral condyle and b) after corrective open-wedge osteotomy and epiphysiodesis of the proximal fibula. 


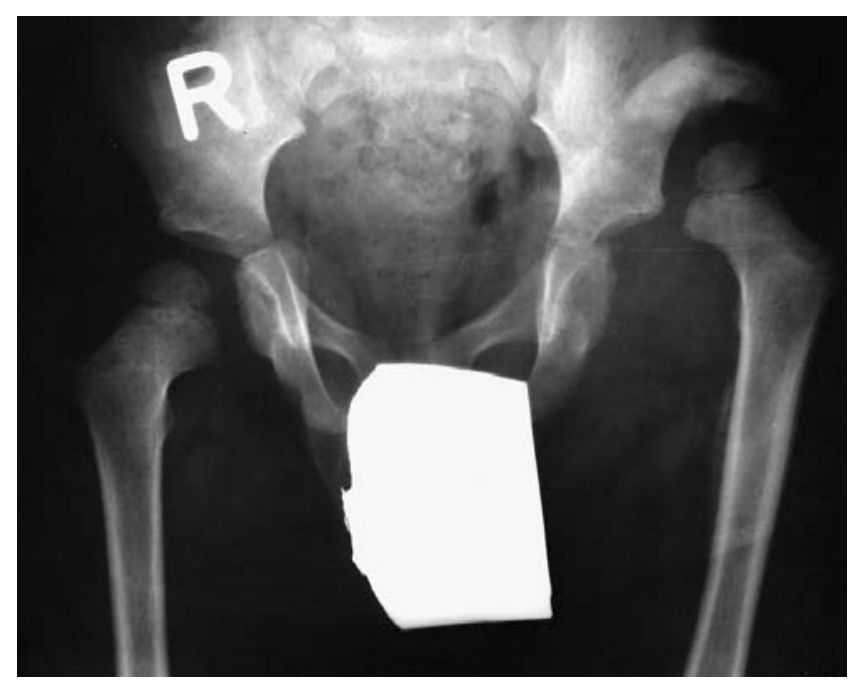

Fig. 5a

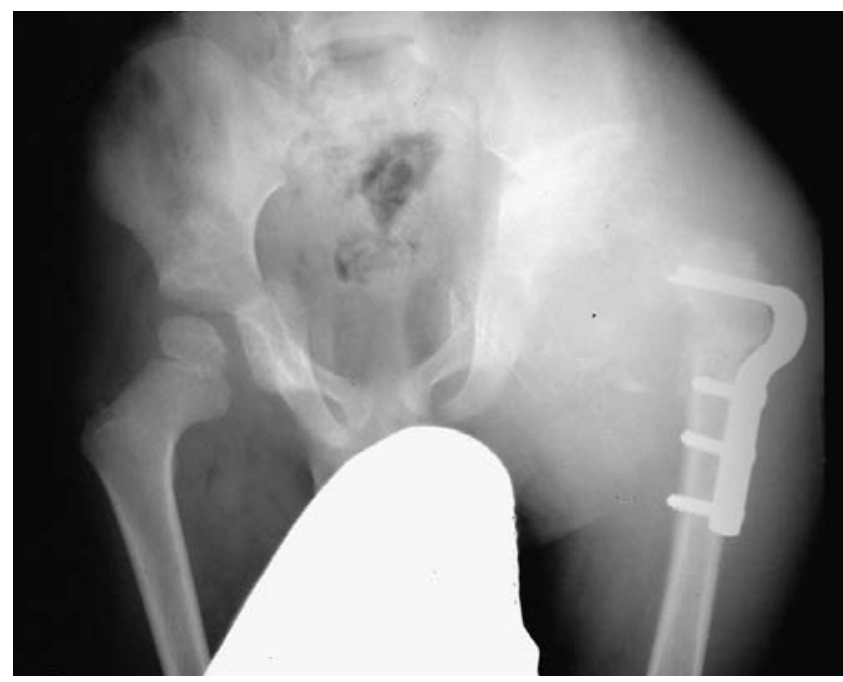

Fig. 5c

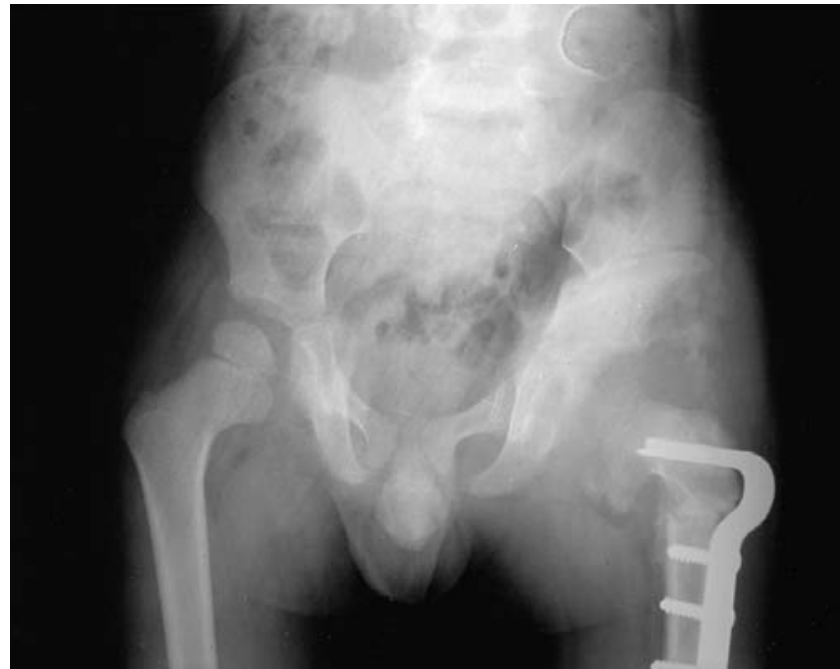

Fig. 5b

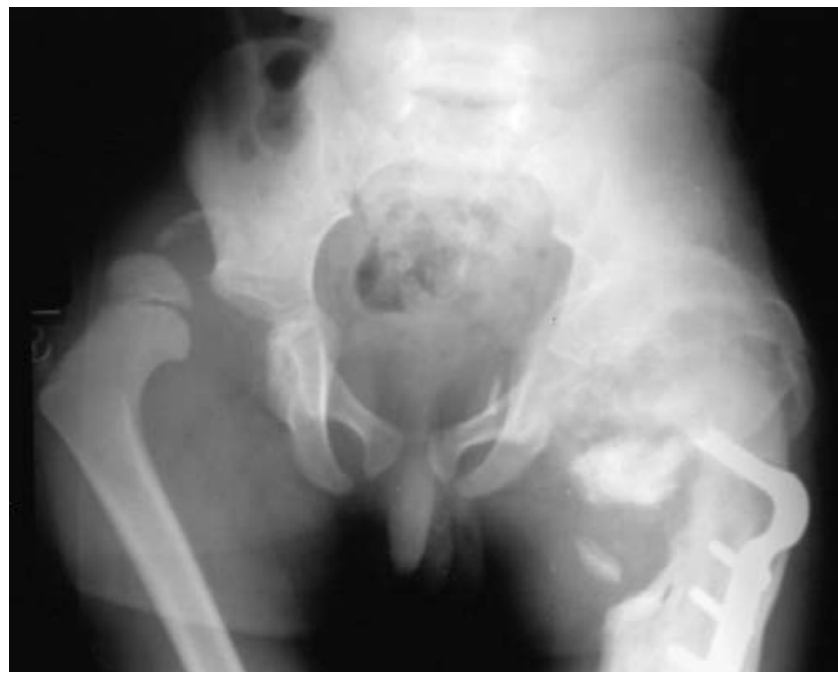

Fig. 5d

Case 4. Radiographs of a dislocation of the hip in a type-C patient showing a) dislocations and calcification of the capsule, b) the result after open reduction, capsulorrhaphy and pelvic and femoral osteotomy, c) redislocation after removal of the spica and d) the final result, bilateral dislocation.

control of blood pressure are normal. Type III, also known as familial dysautonomia or Riley-Day syndrome, is a multisystemic disease affecting mainly Ashkenazi Jews. The clinical features include diminished pain sensation, unexplained fevers, hypertension and postural hypotension caused by defective control mechanisms of temperature and blood pressure. Patients suffer from oropharyngeal dyscoordination and abnormal gastro-oesophageal motility. These cause feeding difficulties, vomiting and recurrent aspiration pneumonia leading to chronic lung disease. Musculoskeletal manifestations include ataxic gait, severe kyphoscoliosis, deformities of the feet and an increased incidence of fractures. Based on our experience ${ }^{19}$ as well as that of Axelrod and Pearson, ${ }^{20}$ we feel that these patients comprise a distinct group separate from all other types of HSAN. Type IV, also known as congenital insensitivity to pain and anhidrosis, is a severe form presenting at infancy.
In addition to their musculoskeletal problems, patients suffer from anhidrosis, defective control of temperature, mental retardation and severe behavioural disturbances. Type $\mathrm{V}$ is again a relatively mild condition selectively affecting nociception.

When trying to apply Dyck's classification to our patients, nine were classifiable: one patient was type I, two were type II and six were type IV. There was, however, considerable variability in clinical features within the same classes as well as between siblings. One additional patient (case 13) had clinical features of type-IV HSAN, although his intelligence and behaviour were normal. The three patients presenting mainly with osseous pathology were not classifiable by Dyck's classification. They all had normal intelligence, and although limb deformities resulting from malunion of fractures or Charcot joints have been documented in earlier studies, the growth disturbances which we 
found have, to our knowledge, not been previously described. We therefore feel that these patients comprise an additional class, type VI, which should be added to Dyck's classification. This is also supported by our genetic findings. The mutations found in four of our patients did not correlate directly with the phenotypic expression. Two patients (cases 1 and 2), despite their Southern Bedouin descent, did not show the 1926-1ns-T mutation found in other patients of similar origins, namely one of our patients (case 3) and nine previously described by Shatzky et al. ${ }^{18}$ Furthermore, additional mutations have been found in other ethnic groups with similar clinical manifestations. ${ }^{21,22} \mathrm{We}$ therefore feel that further research into the genetic, biochemical and electrophysiological aspects of the various subtypes is needed to define the specific pathological entities and allow genetic counselling and prenatal diagnosis. We found the three different types of clinical presentation seen in our patients to be more useful in the prognosis and treatment of their musculoskeletal problems than either the Dyck classification or the genetic information.

One of the major problems in these patients is the differentiation between fractures and infections. Both will usually present at an advanced stage with local swelling and warmth. Radiographs may show early formation of callus. Body temperature is not a reliable indicator, and the ESR and level of C-reactive protein are commonly elevated because of concomitant infections at other sites. Aspiration and cultures should therefore be obtained before undertaking radical debridement to prevent unnecessary surgery and damage to the growth plate. Once the diagnosis of infection has been clearly established, debridement should be as wide as possible to obtain control of the infection. Prevention plays an important role in reducing the extent of infections, especially in type-A patients. They should have custom-fitted shoes and periods of non-weight-bearing to relieve pressure areas. Education regarding local foot care as well as early medical attention is imperative since these can prevent the need for radical surgery. Dislocated joints should be treated by 'watchful neglect'. These joints are painless and mobile. Although Roberts et al ${ }^{15}$ have described successful surgical stabilisation of the hip by a posterior approach, our experience, as well as that of Koster et $\mathrm{al}^{8}$ has been of failure. In addition, the danger of heterotopic ossification and the creation of a stiff joint could be disastrous in an insensate patient.

Growth disturbances should be anticipated in type-B patients. Attempts should be made to control alignment by the application of plaster casts, taking advantage of fractures to correct malalignment. When necessary, corrective osteotomies give good results, although recurrence may occur, and hemiepiphysiodesis may be required. Leg-length discrepancy should be treated by shoe raises or epiphysiodesis since we feel that lengthening procedures are not appropriate in these patients.
The authors would like to thank Professor V. Bialik, Dr L. Copeliovitch and Professor S. Porat for contributing their cases to the study, and Professor S. Moses for reviewing the paper.

No benefits in any form have been received or will be received from a commercial party related directly or indirectly to the subject of this article.

\section{References}

1. Dyck PJ. Normal atrophy and degeneration predominantly affecting peripheral sensory and autonomic neurons. In: Dyck PJ, Thomas PK, Griffin JW, Law PA, Peduslo JF, eds. Peripheral neuropathy. 3rd edition. Philadelphia, etc. W.B. Sanders Company 1993:1065-93.

2. Berkovitch M, Copeliovitch L, Tauber T, Vaknin Z, Lahat E. Hereditary insensitivity to pain with anhidrosis. Pediatr Neurol 1998;10:227-9.

3. Derwin KA, Glover RA, Wojtys EM. Nociceptive role of substance$\mathrm{P}$ in the knee joint of a patient with congenital insensitivity to pain. $J$ Pediatr Orthop 1994;14:258-62.

4. Drummond RP, Rose GK. A twenty-one year review of a case of congenital indifference to pain. J Bone Joint Surg $[\mathrm{Br}]$ 1975;57-B:241-3.

5. Greider TD. Orthopaedic aspects of congenital insensitivity to pain. Clin Orthop 1983;172:177-85.

6. Guidera KJ, Multhopp H, Ganey T, Ogden JA. Orthopaedic manifestations in congenitally insensate patients. J Pediatr Orthop 1990;10:514-21.

7. Guille JT, Forlin E, Bowen JR. Charcot joint disease of the shoulders in a patient who had familial sensory neuropathy with anhidrosis: a case report. J Bone Joint Surg [Am] 1992;74-A:1415-7.

8. Koster G, von Knoch M, Willert HG. Unsuccessful surgical treatment of hip dislocation in congenital sensory neuropathy with anhidrosis. J Bone Joint Surg [Br] 1999;81-B:102-5.

9. Krettek C, Gluer $\mathbf{S}$, Thermann $\mathbf{H}$, et al. Nonunion of the ulna in a ten-month-old child who had type-IV hereditary neuropathy: a case report. J Bone Joint Surg [Am] 1997;79-A:1232-4.

10. Kuo RS, Macnicol MF. Congenital insensitivity to pain: orthopaedic implications. J Pediatr Orthop B 1996;5:292-5.

11. MacEwen GD, Floyd GC. Congenital insensitivity to pain and its orthopedic implications. Clin Orthop 1970;68:100-7.

12. Mazar A, Herold HZ, Vardy PA. Congenital sensory neuropathy with anhidrosis: orthopedic complication and management. Clin Orthop 1976;118:184-7.

13. Okuno T, Inoue A, Izumo S. Congenital insensitivity to pain with anhidrosis: a case report. J Bone Joint Surg [Am] 1990;72-A:279-82.

14. Pinsky L, DiGeorge AM. Congenital familial sensory neuropathy with anhidrosis. J Pediatr 1966;68:1-13.

15. Roberts JM, Taylor J, Burke S. Recurrent dislocation of the hip in congenital indifference to pain: case report with arthrographic and operative findings. J Bone Joint Surg [Am] 1980;62-A:829-31.

16. Rosemberg S, Marie SK, Kliemann S. Congenital insensitivity to pain with anhidrosis (hereditary sensory and autonomic neuropathy type IV). Pediatr Neurol 1994;11:50-6.

17. Swanson AG. Congenital insensitivity to pain with anhydrosis. Arch Neur 1966;8:299-306.

18. Shatzky $\mathbf{S}$, Moses $\mathbf{S}$, Levy $\mathbf{J}$, et al. Congenital insensitivity to pain with anhidrosis (CIPA) in Israeli-Bedouins: genetic heterogenicity, novel mutations in the TRKA/NGF receptor gene, clinical findings, and results of nerve conduction studies. Am J Med Genet 2000;92:353-60.

19. Bar-On E, Floman Y, Sagiv $\mathbf{S}$, et al. Orthopedic manifestations of familial dysautonomia: a review of 136 patients. J Bone Joint Surg [Am] 2000;82-A:1563-70.

20. Axelrod FB, Pearson J. Congenital sensory neuropathies: diagnostic distinction from familial dysautonomia. Am J Dis Child 1984;138:947-54.

21. Greco A, Villa R, Tubino B, et al. A novel NTRK1 mutation associated with congenital insensitivity to pain with anhidrosis. Am J Hum Genet 1999;64:1207-10.

22. Mardy S, Miura Y, Endo F, et al. Congenital insensitivity to pain with anhidrosis: novel mutations in the TRKA (NTRK1) gene encoding a high-affinity receptor for nerve growth factor. Am J Hum Genet 1999;64:1570-9. 